$\mathbb{P}$ periodica polytechnica

Civil Engineering

57/2 (2013) $129-137$

doi: 10.3311/PPci.7169

http://periodicapolytechnica.org/ci

Creative Commons Attribution (1)

RESEARCH ARTICLE

\section{Influence of the compaction method on the bond between steel and concrete in composite columns}

\author{
Elżbieta Szmigiera / Piotr Woyciechowski
}

Received 2013-02-05, revised 2013-03-20, accepted 2013-05-28

\begin{abstract}
The aim of the present paper is to assess the impact of the compaction method on the bond between concrete and steel in composite columns. The full scale laboratory tests show that the bond between vibrated concrete and steel is better than in case of self-compacting concrete. It is indicated that the higher concrete compressive plastic stress level the more strength the bond. The results obtained on the basis of laboratory tests are compared with calculations performed according to the Eurocode 4. Moreover, the bond considered is modeled by the FE method. The measured strains and thus computed stresses compare favorably with the FE predictions.
\end{abstract}

\section{Keywords}

steel-concrete composite columns $\cdot$ steel-concrete bond $\cdot$ selfcompacting concrete

\section{Elżbieta Szmigiera}

Faculty of Civil Engineering, Warsaw University of Technology, Al. Armii Ludowej 16, 00-637 Warsaw, Poland

e-mail: e.szmigiera@il.pw.edu.pl

\section{Piotr Woyciechowski}

Faculty of Civil Engineering, Warsaw University of Technology, Al. Armii Ludowej 16, 00-637 Warsaw, Poland

e-mail: p.woyciechowski@il.pw.edu.pl

\section{Introduction}

The purpose of the research presented in this paper is the assessment of self-compacting concrete (SCC) mix properties with a view to applying SCC mix in steel-concrete composite columns. The main criterion of suitability of SCC for construction of steel-concrete composite columns assumed in the research is the quality of the bond between steel and concrete. A comparative analysis is performed on the results of tests conducted with rectangular hollow sections filled with selfcompacting concrete (Fig. 1) and collated with test results for similar elements filled with vibrated concrete [1].

The steel-concrete composite compression members made of concrete encased or the concrete filled steel sections present considerable technological difficulties in the production process. Relatively small parts of the cross-section of such elements through which concrete mix is introduced require an adequate level of its fluidity as well as resistance to segregation. Compacting concrete mix by vibration causes difficulties and may produce a number of effects which impair the quality of elements. Inserting an immersion vibrator into, most often, narrow spaces between a steel section and the formwork entails the risk of the vibrator coming into contact with the steel section, which leads to segregation in the bond formation area. In addition, the ordinary reinforcement on the cross-section of the element makes the flow of the mix and the use of the vibrator difficult. An alternative solution consisting in the use of external shutter vibrators is difficult to apply in such cases due to high stiffness of the elements to which vibrators can be attached (beam flanges, formwork parts). Those stiff elements dampen vibrations generated by the vibrator and reduce the effectiveness of concrete mix consolidation. The technological difficulties mentioned above lead to the conclusion that the right solution to be applied in the process of concreting composite columns is self-compacting concrete mix (SCC).

Self-compacting concrete can still be considered as a new material in the construction industry, but recently it has been better and better researched, which is made evident in the new standard EN 206-9 "Concrete - Part 9: Additional regulations regarding self-compacting concrete (SCC)" [2], as well as in the European 
"Guidelines for SCC" (EFNARC 2005) [3], regulating the technological and material basics of SCC.

The experience gained so far shows that the use of selfcompacting concrete mix in composite compression members does not substantially affect the load-bearing capacity of columns, in comparison with elements made of vibrated concrete of the same strength. However, the key issue may be the bond between a steel section and the specific type of concrete, namely SCC. The literature of the subject [4-8] indicates that there are clear differences with regard to the bond with steel between vibrated concrete and self-compacting concrete in reinforced concrete structures. Some authors claim that the bond with SCC is better than that with vibrated concrete of the same strength, emphasizing that such a conclusion should be supported by further research [9]. According to other sources, however, the bond strength is lower by about $15 \%$ for SCC than for vibrated concrete [10]. Schiessel and Zilch [11] advance the thesis that there is a specific 'bond mechanism' for SCC which is different from that for vibrated concrete. They support their thesis by, i.e., an even distribution of coarse aggregate and absence of air bubble clusters near the surface of steel in SCC. That results in a different character of the relationship between slip and relative bond in the area of low values of slip (0.1 mm - $0.2 \mathrm{~mm})$. However, all the conclusions mentioned above refer only to research on the bond between concrete and reinforcement bars in reinforced concrete elements. The authors of this paper have not found any research results regarding the bond between concrete and steel at the interface of SCC and steel sections. Experimental assessment of such bond is necessary for verifying the suitability of SCC in steel-concrete composite columns' design. The bond in the steel section - concrete system differs slightly from the bond in the rebar - concrete system, which, in the opinion of the authors, may be of particular importance as regards SCC.

\section{Research program}

\subsection{Tested elements}

The subject of research presented in this analysis were specimens of composite columns, the cross-section of which consisted of two steel double-I sections HE160A filled with concrete (Fig. 1).

The structural steel sections were connected with steel plates on the whole length of the element. The cross-section obtained was similar to a tubular hollow section. The tested elements were filled with self-compacting concrete and with vibrated concrete. Columns filled with SCC were $620 \mathrm{~mm}$ high and columns filled with vibrated concrete were $1250 \mathrm{~mm}$ high (see tab. 1 and Fig. 2). The difference in height between two series was caused by materials reasons (availability of double-I sections of the same material properties). For making final results comparable, all the measured values were referred to the real surface of bonding, resulting from the height of specimen.
On the whole, the elements tests included four models filled with SCC and three with vibrated concrete.

\subsection{Designing and properties of concrete used in tested models}

The research program included making columns of two concrete types (self-compacting and vibrated) with the similar cement content and water-cement ratio. Assumed cement content was app. $350 \mathrm{~kg} / \mathrm{m}^{3}$ and w/c value was $0.52 \pm 0.02$. Vibrated concrete composition was designed as typical construction concrete with slump class $\mathrm{S} 2$.

Self-compacting concrete composition was designed on the basis of EFNARC Guidelines [3] and European Standard EN 206-9 [2]. According to these documents composite columns could be categorized as "walls and piles" or "tall and slender elements". Both categories require class SF2 or SF3 of slump flow and class VS1, VS2, VF1 or VF2 of viscosity $t_{500}[2,3]$. Analysis of conditions of concreting elements in the laboratory led the authors to the following assumptions: SF2 (660-750 mm) class of slump flow and VS2 $\left(t_{500}>2 \mathrm{~s}\right)$ class of viscosity.

Designing of concrete composition was performed by experimentally-computed method elaborated in Department of Building Materials Engineering of Warsaw University of Technology. The method is based on Densified Mixture Design Algorithm concept provided by Chao-Lung Hwang and Chih Ta Tsai [12] and considerations contained in [3, 13, 14]. Designing procedure includes 11 computational and experimental steps:

1. Choosing of maximal grain and content of $-W_{\mathrm{Kg}}$ in the limits of $750 \div 1000 \mathrm{~kg} / \mathrm{m}^{3}$ and fine aggregate $(0 / 4 \mathrm{~mm})$ content - Pp in the limits of $48 \div 55 \%$ (acc. to EFNARC-a [3]), than calculation of fine aggregate content in $1 \mathrm{~m}^{3}\left(W_{\mathrm{P}}\right)$,

2. Experimental determination of the percentage of each fraction of coarse aggregate in order to have the minimum bulk density of aggregate mixture,

3. Selecting of type of powder material (for example fly ash, silica fume etc.) and its content in concrete $\left(W_{\mathrm{M}}, \mathrm{kg} / \mathrm{m}^{3}\right)$, taking into consideration expected mix and concrete properties.

4. Calculation of free spaces volume in $1 \mathrm{~m}^{3}$ of coarse and fine aggregate and powder material, $V_{v}, \mathrm{~m}^{3}$, as follow:

$$
V_{v}=1-\left(\frac{K}{\rho_{K}}+\frac{W_{M}}{\rho_{M}}\right)
$$

where: $K-$ is the mass content of fine and coarse aggregate $\left(W_{\mathrm{Kg}}+W_{\mathrm{p}}\right), \mathrm{kg} ; W_{M}-$ is the mass content of powder material, $\mathrm{kg}$; $\rho_{K} \rho_{M}-$ are the densities respectively of aggregate and powder material, $\mathrm{kg} / \mathrm{m}^{3}$.

5. Assumption of coefficient of free spaces filling with cement paste, $n$ in the limits as follows:

$$
n \in[1.2,2.0]
$$

6. Calculation of cement paste volume, $V p, \mathrm{~m}^{3}$, as follow :

$$
V_{p}=n \cdot V_{v}
$$



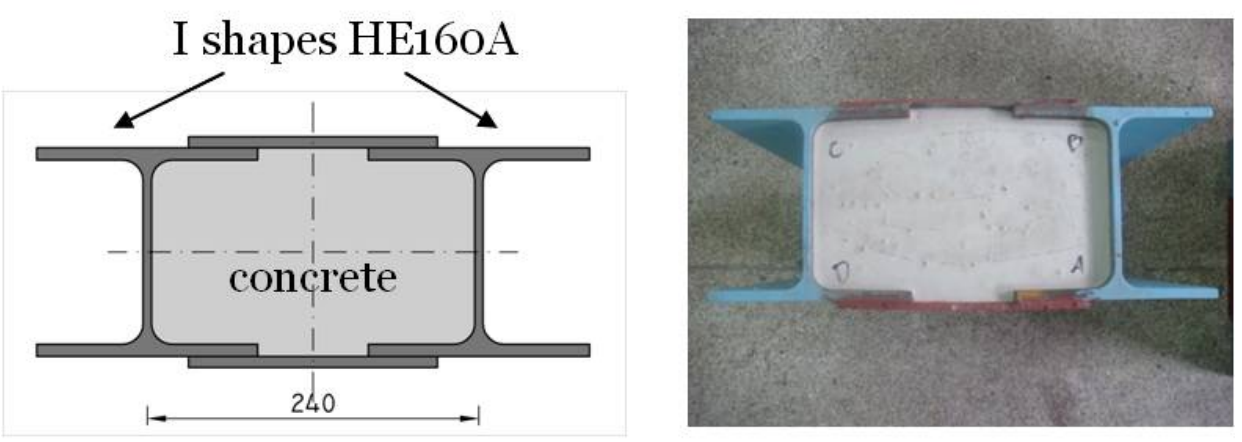

Fig. 1. Transverse cross-section of tested column models

Tab. 1. Characteristics of specimens

\begin{tabular}{|c|c|c|c|c|c|}
\hline Type of series & Models symbol & $\begin{array}{c}\text { Height of } \\
\text { specimens } \\
\text { [mm] }\end{array}$ & $\begin{array}{c}\text { Connection } \\
\text { between } \\
\text { I-shapes }\end{array}$ & $\begin{array}{l}\text { Strength class } \\
\text { of concrete }\end{array}$ & Class of steel \\
\hline \multirow{4}{*}{ filled with SCC } & SCC1 & \multirow{4}{*}{620} & \multirow{7}{*}{$\begin{array}{l}\text { continuous } \\
\text { steel plates }\end{array}$} & \multirow{4}{*}{ C50/60 } & \multirow{7}{*}{ S235JRG2 } \\
\hline & SCC2 & & & & \\
\hline & ScC3 & & & & \\
\hline & SCC4 & & & & \\
\hline filled with & SV7 & \multirow{3}{*}{1250} & & \multirow{3}{*}{ C30/37 } & \\
\hline vibrated & SV8 & & & & \\
\hline concrete & SV9 & & & & \\
\hline
\end{tabular}

SV
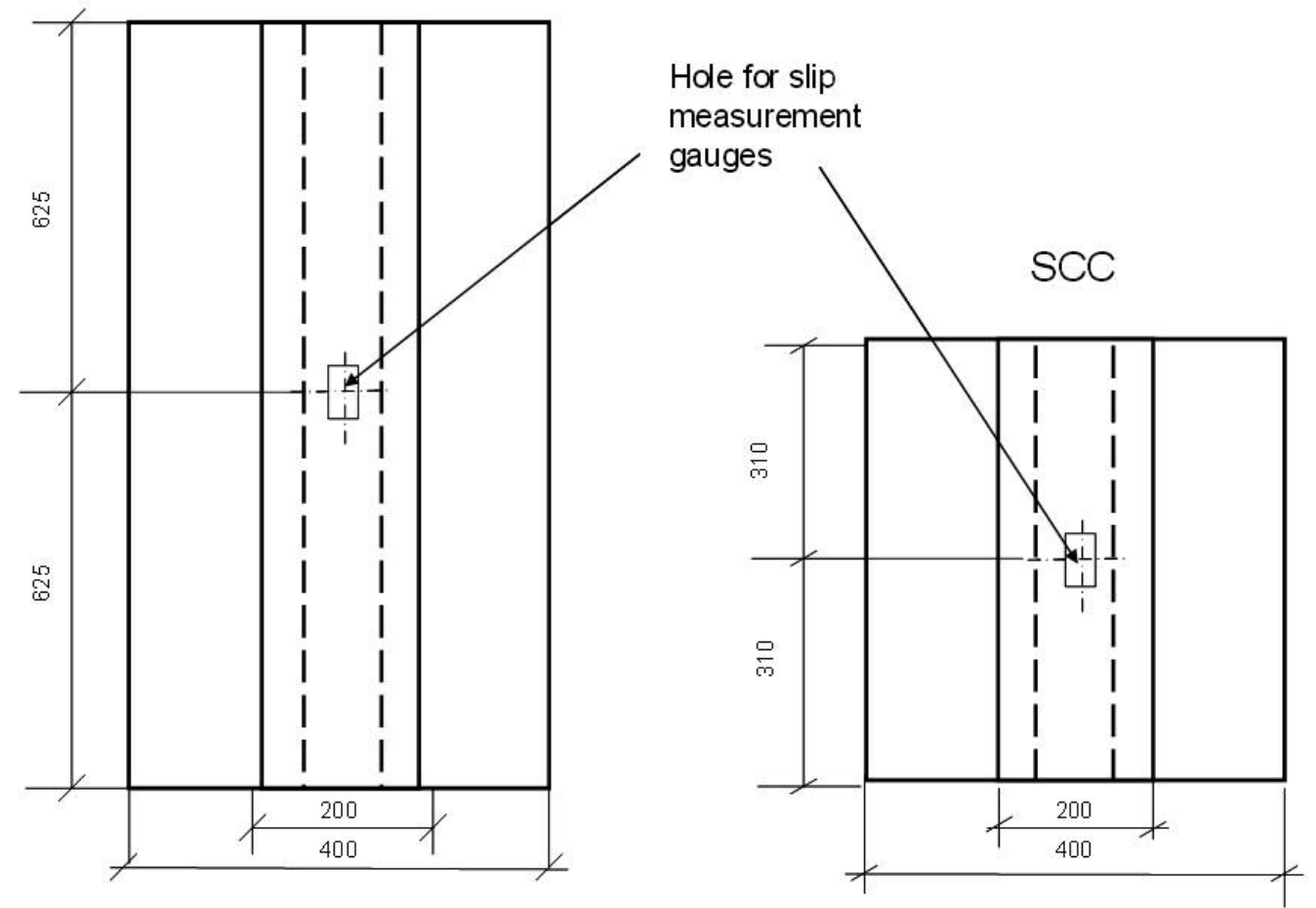

Fig. 2. View and dimensions of specimens 
7. Assumption of water-binder coefficient $\lambda$, as follow:

$$
\lambda=W /\left(C+W_{M}\right)
$$

where $W, C, W_{\mathrm{M}}$ - are the water, cement and powder material content, $\mathrm{kg} / \mathrm{m}^{3}$.

8. Calculation of cement content in $1 \mathrm{~m}^{3}$, assuming that powder material is a part of aggregate:

$$
C=\frac{V_{p}-\frac{\lambda \cdot W_{M}}{\rho_{W}}}{\frac{\lambda}{\rho_{W}}+\frac{1}{\rho_{C}}}
$$

where: $\rho_{w}-$ is the water density, $\mathrm{kg} / \mathrm{m}^{3} ; \rho_{c}-$ is the cement density, $\mathrm{kg} / \mathrm{m}^{3}$

9. Calculation of the required amount of water from the transformation of formula (4)

10. Adjustment of the composition to the 1 cubic meter.

11. Making a testing mixture and determining the appropriate dosage of superplasticizer to achieve the assumed slump flow and viscosity classes, making samples for testing compression strength.

If there is no satisfactory self-compaction, symptoms of segregation, too high needed dosage of superplasticizer, etc. it is necessary to return to the step 5 and change the value $n$ (coefficient of free spaces filling with cement paste). Then it have to repeat further computational and experimental steps.

Designing concrete mixture for composite columns, gravel aggregate $D_{\max }=16 \mathrm{~mm}$ river sand $0 / 2 \mathrm{~mm}$, Portland cement CEM I 42,5R and siliceous fly ash, as an additive most frequently used for SCC [14]. Fly ash content in concrete was adopted on the level of ca. $90 \mathrm{~kg} / \mathrm{m}^{3}$. Following the indicated procedure, the results given in Table 2 were obtained.

\subsection{Conducted tests}

Column specimens were subjected to compressive axial force in a hydraulic compression machine DB 600 (Fig. 3).

Steel elements were filled with concrete in such a way as to leave hollow space $50 \mathrm{~mm}$ deep at the bottom. That allowed column models to rest solely on steel parts of the cross-section while undergoing tests in the hydraulic press, and the void that was left enabled concrete to slip along surfaces of steel sections.

Compression load was applied evenly to the concrete part of the cross-section. The load was introduced through two rigid steel plates $60 \mathrm{~mm}$ thick in all, which fitted closely the dimensions of the concrete core (Fig. 3 a).

In addition to load values, values for slip of the concrete core along the steel part of the section were recorded (Fig. $3 \mathrm{~b}$ ). The measurements were taken using sensors placed symmetrically on both sides of the tested elements. Strain gauges were fixed in the holes, which were cut at the central part of batten plates in half of the column height, after the period of concrete hardening. Double measurement of the slip allowed to have constant supervision of load being introduced axially and, consequently, to achieve more accurate results. The load increased until breaking of the bond at the interface of concrete and steel, i.e., to the maximum value of load achieved in the press.

It was observed during the tests that an increase in load introduced resulted in gradual sinking of the steel plate in the element, which was registered as a slight, measured in micrometers, displacement of the concrete on the length of the surfaces of the steel sections. That observation can be attributed to gradual breaking of the bond between steel and concrete.

\section{Analysis of test results}

\subsection{Introduction}

The authors of the present paper have not found recommendations concerning the design of composite compression elements with the use of SCC either in the literature of the subject or in the available standards regulations. Therefore, the results obtained in the tests described in part 2 of this paper can only be compared with recommendations for structures made of vibrated concrete.

Provisions concerning adequate bond in composite columns made of vibrated concrete are given in 6.7.4 of EN 1994-1-1 standard [15].

In contrast with composite elements subjected to bending, in which provision of connectors at the interface of steel and concrete is obligatory, in compression members connection can, according to [15], be achieved by depending on the natural adhesion between these materials. The arrangement of shear connectors should be determined on the basis of distribution of design longitudinal shear in cases where it exceeds the design shear load, the value for which is given in Table 3, quoted after [15]. The table referred to concerns situations where the surface of the steel section in contact with the concrete is unpainted and free from oil, grease and loose particles of scale or rust.

Values given in the Table 3 indicate that the standard [15] does not take into account how the strength and type of concrete influence the value of shear load between the two materials, and connects this value solely to the type of a cross-section without regard to its area.

\subsection{Test results}

Fig. 4 presents the displacement (slip) of concrete relative to the steel as the load increased for vibrated and SCC concrete, respectively

It can be established on the basis of the graphs that for both types of concrete the curves reflecting that relationship are similar. One observes that for low values of load, the amount of slip registered is negative. That may be interpreted as resulting from the fact that the whole element is subject to shortening because the bond between the two materials in the initial phases of load introduction is strong enough, despite the load being transmitted only through the concrete core. Only after the load introduced exceeds the value corresponding to maximum negative slip (Fig. 4 and $4 \mathrm{~b}$ ), the bond at the interface of concrete and steel gradually weakens, which eventually leads to its breaking. 
Tab. 2. Composition and properties of concretes used in tests

\begin{tabular}{|c|c|c|c|c|}
\hline \multicolumn{5}{|c|}{ Composition and properties of concrete } \\
\hline Component & \multicolumn{2}{|c|}{ Self-compacting concrete } & \multicolumn{2}{|c|}{ Vibrated concrete } \\
\hline CEM I 42.5R, $\mathrm{kg} / \mathrm{m}^{3}$ & \multicolumn{2}{|c|}{354} & \multicolumn{2}{|c|}{354} \\
\hline Siliceous fly ash, $\mathrm{kg} / \mathrm{m}^{3}$ & \multicolumn{2}{|c|}{89} & \multicolumn{2}{|c|}{-} \\
\hline Property & Mean value & Standard qualification & Mean value & Standard qualification \\
\hline$w / c(w / b)$ ratio & $0.5(0.4)$ & - & 0.54 & - \\
\hline Slump flow, $d[\mathrm{~mm}]$ & 670 & SF2 & - & - \\
\hline Slump, $\mathrm{mm}$ & - & - & 70 & S2 \\
\hline Viscosity, $t_{500}[\mathrm{~s}]$ & 3.5 & VS2 & - & - \\
\hline $\begin{array}{c}\text { Compression strength, } \\
{[\mathrm{MPa}]}\end{array}$ & 66.7 & $\mathrm{C} 50 / 60$ & 43.8 & $\mathrm{C} 30 / 37$ \\
\hline $\begin{array}{l}\text { Tensile splitting strength, } \\
\text { [MPa] }\end{array}$ & 5.8 & - & 5.4 & - \\
\hline
\end{tabular}

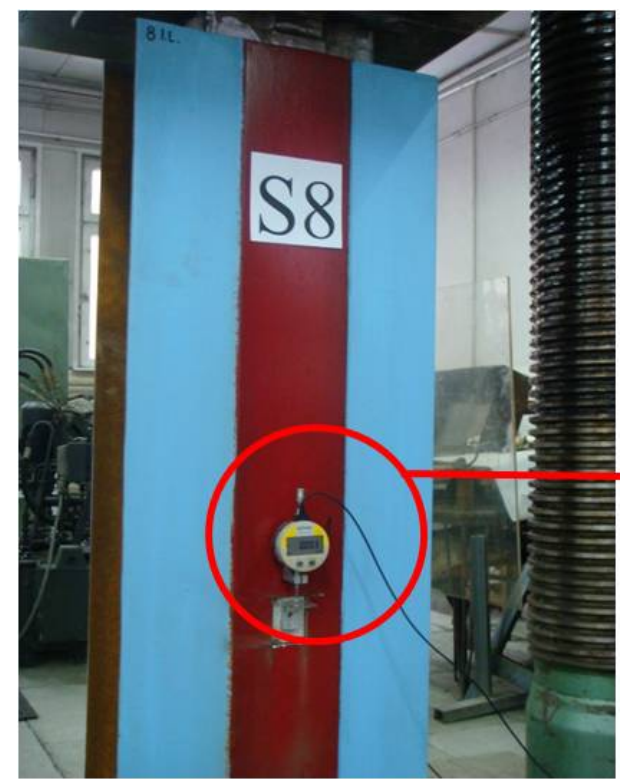

a)

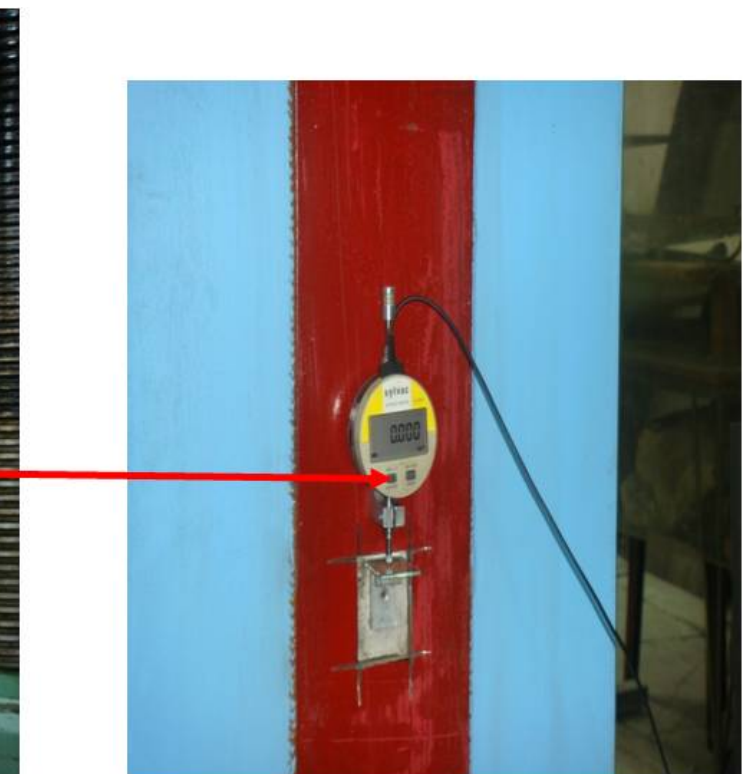

b)

Fig. 3. Test stand: a) element made of vibrated concrete before tests in the hydraulic press, b) measurement of the slip of concrete at the interface of concrete and steel

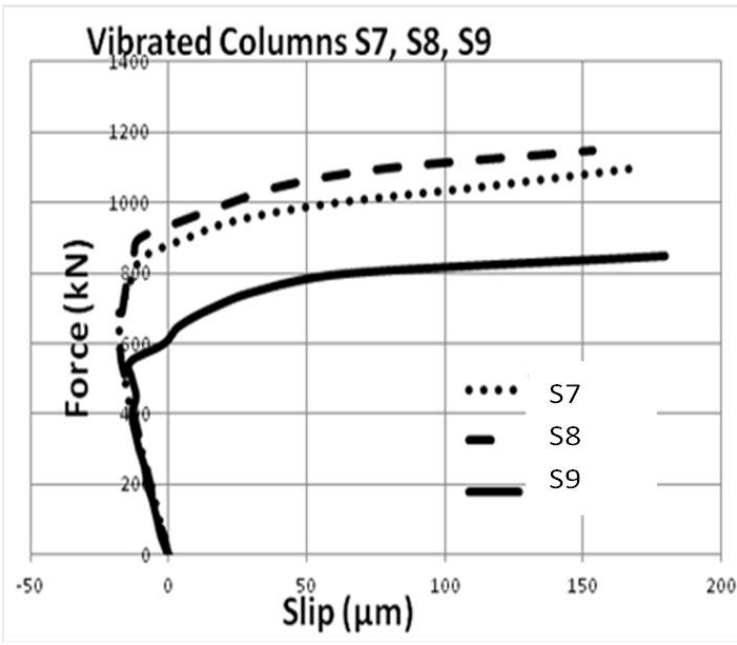

a)

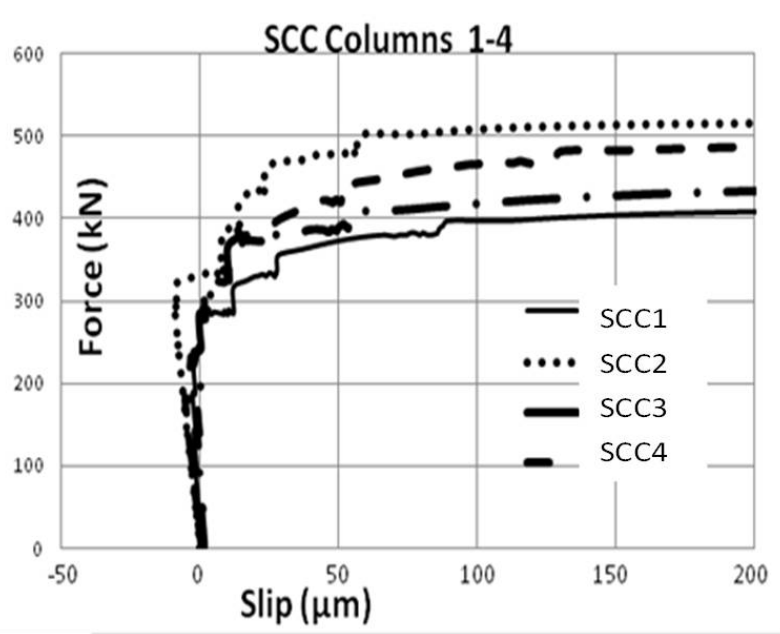

b)

Fig. 4. The displacement of concrete relative to the steel as the load increases: a) for vibrated concrete SV (7-9), b) for SCC (1-4) 
Table 4 presents the tests results for the slip in elements filled with SCC, and then for those filled with vibrated concrete, tests for which were conducted previously by one of the authors of this paper and published in [1, 16]. Columns 4 and 5 of the table 4 give load values, maximum and that accompanying initiation of the slip of concrete relative to the steel, respectively (see Fig. 4). Average shear stresses corresponding to those load values are given in columns 7 and 8. Maximum values of shear stress for both types of concrete are practically identical, whereas shear stress values corresponding to the load values which initiated the slip are considerably different (see Table 5.

Tab. 3. Design shear strength $\tau_{\mathrm{Rd}}[15$

\begin{tabular}{cc}
\hline Type of cross section & $\tau_{\mathrm{Rd}}\left[\mathrm{N} / \mathrm{mm}^{2}\right]$ \\
\hline Completely concrete encased steel sections & 0.30 \\
\hline Concrete filled circular hollow sections & 0.55 \\
\hline Concrete filled rectangular hollow sections & 0.40 \\
\hline Flanges of partially encased sections & 0.20 \\
\hline Webs of partially encased sections & 0.00 \\
\hline
\end{tabular}

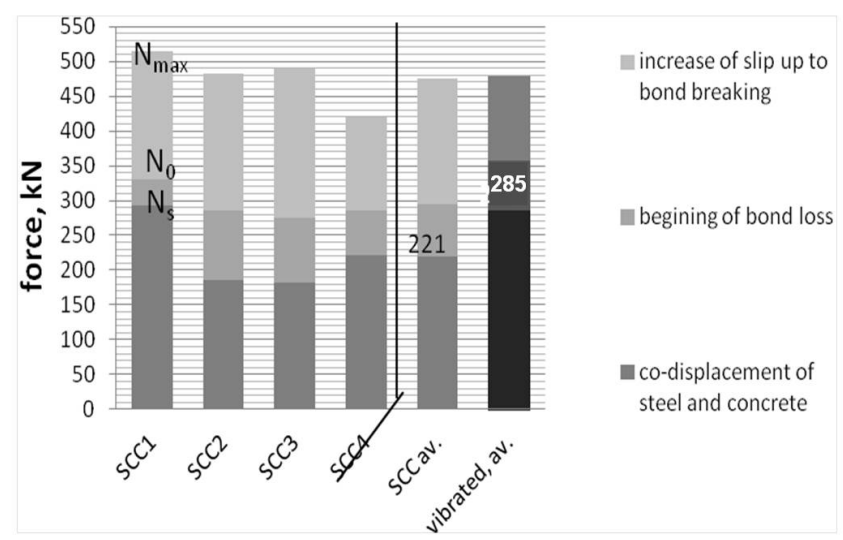

Fig. 5. Phases of breaking of the bond as load increases while testing models made of SCC and of vibrated concrete, where: SCC1-SCC4 - load values for individual elements; SCCav, vibrated,av - average load values; $N_{\mathrm{S}}, N_{0}, N_{\max }-$ loads corresponding to maximum negative slip, zero slip, breaking of the bond

Since the tests were conducted on elements of different height (resulting in different areas of bond - Table 4, col. 2), to compare the tests results it was necessary to translate the loads for vibrated concrete to values referred to the area of bond in the SCC elements (Fig. 5).

Absolute load values, at which the process of breaking of the bond is initiated, are different. In the result, the ratios of those loads to breaking loads at which the bond is broken are different accordingly (see Fig. 4). It can be noted that in vibrated concrete the process of adhesive forces weakening starts at a higher $N_{0} / N_{\max }$ ratio, whereas the speed with which the process takes place is similar for both types of concrete (difference is constant between $N_{0} / N_{\max }$ and $N_{\mathrm{S}} / N_{\max }$ ). Intuitively, it was expected that breaking load values will be higher for concrete of greater strength (i.e., the SCC). However, for both types of concrete the breaking load is the same despite different compressive strengths (cf. Tables 4 and 5), which might lead to a conclusion that the use of self compacting concrete impaired the strength of bond.

\subsection{Interpretation}

In order to compare average values of shear stress obtained in the tests (see Table 4, col.7) with the values given in Table 3 , design values for the former were determined (Table 5). For that purpose, the partial coefficient $\gamma_{\mathrm{vs}}=1,25$ was taken, as recommended in [15] to be applied in longitudinal shear calculations.

From the analysis of shear stresses provided in Table 5 it follows that the average design value obtained in the tests of the two types of elements $\tau_{\mathrm{md}}$ is over twice as high as the $\tau_{\mathrm{Rd}}=0.40 \mathrm{~N} / \mathrm{mm}^{2}$ given in the standard [15] for rectangular hollow sections, which are the nearest to the tested models as regards the cross-section shape. It should be stressed though that stresses calculated for loads which initiated the slip are close to standard values.

Table 5. Column 5 gives values of ultimate relative bond $\tau_{\mathrm{m}} / f_{\mathrm{c}}$, i.e., in relation to concrete compressive strength. Those data show that higher result have been obtained for vibrated concrete. In the same time, the two types of concrete compared in the tests, despite of similar w/c ratios $(0.5$ for SCC and 0.54 for vibrated concrete) and the same cement content, differ by about $50 \%$ with regard to compressive strength, which is due to the higher binder content (use of fly ash) and a higher homogeneity characteristic of SCC.

\section{Finite Element model development}

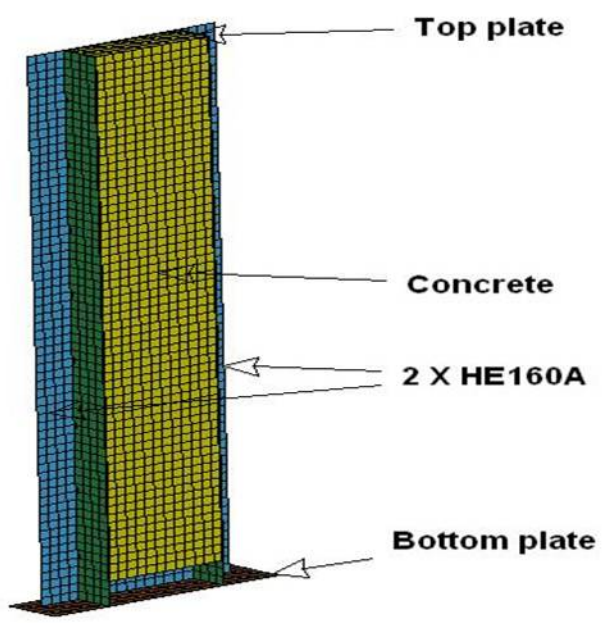

Fig. 6. Cross-section (right) of the FE model

Results of laboratory investigations were the inspiration for the present authors to perform numerical analysis of tested elements. The paper presents the first stage of the investigation focused on the verification of options for modelling concrete steel interactions and validation through comparison with the experimental data. The main objectives of the FE analysis are: development and validation of a reliable numerical model suitable for parametric study, determination of stress distribution in 
Tab. 4. Results of bond testing for composite models filled with SCC and vibrated concrete

\begin{tabular}{|c|c|c|c|c|c|c|c|}
\hline \multirow{3}{*}{ Models symbol } & \multirow{3}{*}{ Contact area $A_{\mathrm{c}-\mathrm{s}}\left[\mathrm{mm}^{2}\right]$} & \multicolumn{3}{|c|}{ Load $\left[10^{3} \mathrm{~N}\right]$} & \multicolumn{3}{|c|}{ Shear stresses $\left[\mathrm{N} / \mathrm{mm}^{2}\right]$} \\
\hline & & \multicolumn{2}{|c|}{$N_{\max }$} & \multirow{2}{*}{$N_{\mathrm{s}}$ average } & \multicolumn{2}{|c|}{$\tau_{\mathrm{m}}=N_{\max } / A_{\mathrm{c}-\mathrm{s}}$} & \multirow{2}{*}{$N_{\mathrm{s}} / A_{\mathrm{c}-\mathrm{s}}$} \\
\hline & & for element & average & & for element & average & \\
\hline 1 & 2 & 3 & 4 & 5 & 6 & 7 & 8 \\
\hline SCC1 & \multirow{4}{*}{425068.2} & 514.8 & \multirow{4}{*}{476.5} & \multirow{4}{*}{221.0} & 1.20 & \multirow{4}{*}{1.12} & \multirow{4}{*}{0.52} \\
\hline SCC2 & & 483.0 & & & 1.14 & & \\
\hline SCC3 & & 489.6 & & & 1.15 & & \\
\hline SCC4 & & 418.6 & & & 0.99 & & \\
\hline SV7 & \multirow{3}{*}{914912.3} & 1085.0 & \multirow{3}{*}{1043.3} & \multirow{3}{*}{613.0} & 1.19 & \multirow{3}{*}{1.14} & \multirow{3}{*}{0.67} \\
\hline SV8 & & 1190.0 & & & 1.30 & & \\
\hline SV9 & & 855.0 & & & 0.93 & & \\
\hline
\end{tabular}

Tab. 5. Comparison of shear stress for columns models filled with SCC and vibrated concrete

\begin{tabular}{ccccc}
\hline Models symbol & $\begin{array}{c}\text { Design average } \\
\text { shear stress } \\
\tau_{\mathrm{md}}\left[\mathrm{N} / \mathrm{mm}^{2}\right]\end{array}$ & $\begin{array}{c}\text { Design stress } \\
\text { corresponding } \\
\text { to the beginning } \\
\left.\text { of slip [N/mm } \mathrm{mm}^{2}\right]\end{array}$ & $\begin{array}{c}\text { Concrete } \\
\text { compressive } \\
\text { strength } \\
f_{\mathrm{cm}}[\mathrm{MPa}]\end{array}$ & $\begin{array}{c}\text { Relative bond } \\
\tau_{\mathrm{m}} / f_{\mathrm{cm}}\end{array}$ \\
\hline SCC & 2 & 3 & 4 & 5 \\
\hline SV & 0.90 & 0.42 & 66.7 & 0.017 \\
\hline
\end{tabular}

the steel concrete interface, and computer simulation of damage evolution in the concrete to steel bond. The FE model was prepared with the help of graphical processor LSPREPOST and all calculations were conducted using general purpose FE program LS-DYNA®with explicit time integration [17].

The numerical results presented below were calculated for the series of columns filled with vibrated concrete and marked during the experiment as SV7-SV9 (see Table 4). In the present authors' opinion it is not possible to take into account the concrete compaction effect in FE modelling.

The steel elements of the investigated column $(2 \times$ I-beam HE160A and continuous connecting sheet) were modelled using 4-noded fully integrated shell elements with appropriate thicknesses.

An elastic - plastic material model with strain hardening was used for steel modelling with the following parameters: density $\rho=7.85 \times 10^{-9} \mathrm{t} / \mathrm{mm}^{3}$, modulus of elasticity $E=205 \mathrm{GPa}$, Poisson's ratio $v=0.3$. Concrete core of the column is modelled with 8-noded fully integrated brick elements. In the first stage it is assumed that the stresses in concrete are within elastic range and the only damage is possible for the bond between concrete and steel. Consequently elastic material model was used with the following concrete parameters: $\rho=2.4 \times 10^{-9} \mathrm{t} / \mathrm{mm}^{3}$, $E=27.4 \mathrm{GPa}$ and Poisson ratio $v=0.18$. Bond of concrete to steel elements is modeled using contact AUTOMATIC ONE WAY SURFACE TO SURFACE TIEBREAK, where failure criterion is described by following formula [17]:

$$
\left(\frac{\left|\sigma_{n}\right|}{\sigma_{n f}}\right)^{2}+\left(\frac{\left|\tau_{s}\right|}{\tau_{s f}}\right)^{2} \leq 1
$$

where: $\sigma_{\mathrm{n}}, \tau_{\mathrm{s}}-$ existing normal and shear stress, $\sigma_{\mathrm{nf}}, \tau_{\mathrm{sf}}-$ normal and shear failure stress.
After the failure stress criterion is met, damage is a linear function of the distance between points initially in contact. When the distance is equal to PARAM damage is fully developed and contact behaves as SURFACE_TO_SURFACE. The loading was represented by a prescribed motion of rigid plate connected with the top face of the concrete core. The boundary conditions are represented by displacement constraints of the nodes at the bottom plate (see Fig. 6).

The preliminary results show that the predictable stress distribution in concrete core and in steel sheeting is non-uniform (Fig. 7) and for the axial loading the value of shear stresses doesn't reach the maximum level obtained in tests. As it is shown in Fig. 7, the concrete core is mostly loaded at the top, close to the load application face, and steel sheeting - at the bottom, close to the base. Results also show that for modeling of bond, application of average shear stress is not representative and should be determined in other way. The search of the proper model assumption will be conducted in the future step of the numerical analysis.

\section{Conclusions}

The analysis of international literature carried out by the present authors shows that no results of research into composite steel - concrete structures made of self-compacting concrete have been published. Eurocode $4[15]$ does not refer to SCC, either. In the opinion of the present authors, the SCC technology can be applied on a large scale in composite columns execution, if the specific properties and behaviour of SCC in combination with structural steel will be examined.

In the present paper the results of tests conducted on models of battened steel columns filled with SCC have been shown. For the more in-depth analysis, the research results have been com- 


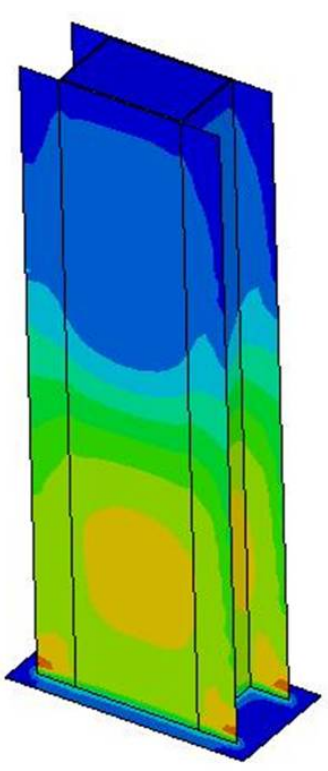

Fringe Levels

$1.275 e+02$

$1.148 \mathrm{e}+02$

$1.020 \mathrm{e}+02$

$8.928 \mathrm{e}+01$

$7.653 \mathrm{e}+01$

$6.377 \mathrm{e}+01$

$5.102 \mathrm{e}+01$

$3.826 \mathrm{e}+01$

$2.551 \mathrm{e}+01$

$1.275 \mathrm{e}+01$

$0.000 \mathrm{e}+00$

Fig. 7. Effective stress distribution in steel and concrete elements

pared with the recommendations of the standard for composite steel-concrete structures [15], as well as with the results of previous research into the bond between vibrated concrete and steel done by the present authors. As a result of the analysis, the following conclusions have been reached:

- recommendations given in existing standards with regard to determining design shear stress do not include concrete compressive strength but only the type and shape of composite sections;

- assuming that the bond between concrete and steel is linked to concrete compressive strength, conclusions may be drawn that the use of SCC decreases steel-concrete bond in comparison with vibrated concrete; decrease of relative bond $\tau_{m} / f_{c m}$ as much as ca $35 \%$ was observed due to the use of SCC (see Table 5 col. 5) but the maximum values of breaking load was ca $0.9 \mathrm{~N} / \mathrm{mm}^{2}$ for both types of concrete;

- the values of shear stress $\tau_{\mathrm{md}}$ calculated on the basis of maximum breaking load values (ca $0.9 \mathrm{~N} / \mathrm{mm}^{2}$ for both types of concrete) are more than twice higher than standard values given for shear strength $\tau_{\mathrm{Rd}}$ for rectangular hollow sections $\left(0.4 \mathrm{~N} / \mathrm{mm}^{2}\right)$, while the values of shear stress at the beginning of the slip (ca $0.4-0.5 \mathrm{~N} / \mathrm{mm}^{2}$ for both types of concrete) are close to $\tau_{\mathrm{Rd}}$

- the preliminary results from FE analysis show that the predictable stress distribution in concrete core and in steel sheeting is non-uniform; also the values of average shear stress obtained from tests and numerical calculations are different; in author's opinion it causes from dimension of models, assumed to tests. It is clear that the smaller specimens give more uniform distribution of stresses; on the other hand, the

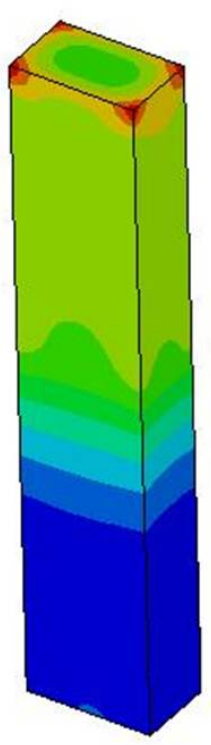

Fringe Levels

$2.881 e+01$

$2.593 e+01$

$2.305 e+01$

$2.017 \mathrm{e}+01$

$1.729 \mathrm{e}+01$

$1.441 \mathrm{e}+01$

$1.154 \mathrm{e}+01$

$8.656 e+00$

$5.777 e+00$

$2.898 \mathrm{e}+00$

1.880 e -02 values of average shear stresses when testing higher elements are more closed to the stresses occurred in the real structure.

The conclusions presented above need to be verified in further tests, the more so that in the literature there is no available results of testing bond between SCC and steel in composite members. It is difficult, however, to compare obtained results with any research on the rebar-concrete bond in reinforced concrete structures. In the opinion of the authors, the mechanism of bond formation in reinforced concrete structures is different from that observed in composite steel-concrete structures. The difference results from the influence on that mechanism exerted by such factors as the direction of laying concrete in relation to the angle of the bar axis on the cross-section, the depth of placing the rebar, as well as its surface profile. Those problems are not encountered in manufacturing steel-concrete columns composed of steel sections and concrete.

\section{References}

1 Szmigiera E, Woyciechowski P, Influence of self-compacting concrete on steel-concrete bond in composite columns, Dni Betonu, (Wisła, Poland, October 2010 ), In: Dni betonu - Tradycja i nowoczesność, Poski Cement, 2010, pp. 797-806. in Polish.

2 EN 206-9 Concrete - Part 9: Additional Rules for Self-compacting Concrete (SCC), 2011.

3 Guidelines for SCC, EFNARC, 2005.

4 Cattaneo S, Rosati G, Bond between steel and self-consolidating concrete: Experiments and modeling, ACI Structural Journal, 106, (2009), 540-550.

5 Desnarck P, Taerwe L, De Schutter G, Experimental determination of bond strength of reinforcing bars in self-compacting concrete, 5th Int. RILEM Symp. on SCC, ( Ghent, Belgium ), In: Proceedings of 5th Int. RILEM Symp. on SCC, RILEM, 2007, pp. 659-664.

6 Yin-Wen Chan, Yu-Sheng Chen, Yi-Shi Liu, Development of bond strength of reinforcement steel in self-consolidating concrete, ACI Structural Journal, 100, (2003), 490-498. 
7 Hunaiti Y M, Bond strength in battened composite columns, Journal of Structural Engineering, 117, (1991), 699-714, DOI 10.1061/(ASCE)07339445(1991)117:3(699).

8 Hunaiti Y M, Aging effect on bond strength in composite sections, Journal of Materials in Civil Engineering, 6/4, (1994), 469-483, DOI 10.1061/(ASCE)0899-1561(1994)6:4(469).

9 Klug Y, Holschemacher K, Comparison of the hardened properties of self compacting and normal vibrated concrete, 3th Int. RILEM Symp. on SCC, ( Reykjavik, Iceland ), In: Proceedings of 3th Int. RILEM Symp. on SCC, RILEM, 2003, pp. 596-605.

10 König G, Holschemacher K, Dehn F, Weiße D, Self-compacting concrete time development of material properties and the bond behaviour, 2th Int. RILEM Symp. on SCC, ( Tokyo, Japan ), In: Proceedings of 2nd Int. RILEM Symp. on SCC, RILEM, 2001, pp. 507-516.

11 SchiessI A, Zilch K, The effect of the modified composition of SCC on shear and bond behavior, 2th Int. RILEM Symp. on SCC, ( Tokyo, Japan ), In: Proceedings of 2nd Int. RILEM Symp. on SCC, RILEM, 2001, pp. 501506.

12 Chao-Lung Hwang, Chih Ta Tsai, The Application of a Geometry Concept to Solve Algebraic Solution in DMDA Method, 4th Int. RILEM Symp. on SCC, ( Chicago, USA ), In: Proceedings of 4th Int. RILEM Symp. on SCC, RILEM, 2005, pp. 1011-1021.

13 Skarendahl A, Petersson 0, Self compacting concrete. State-of-the-art report, 28 RILEM TC 174, 2000.

14 Woyciechowski P, Chudan A, Jackiewicz-Rek W, Investigation on high volume fly ash self-compacting concrete, Inżynieria i Budownictwo, 2, (2006), 91-93. in Polish.

15 EN 1994-1-1 Eurocode 4: Design of composite steel and concrete structures. Part1-1: General rules and rules for buildings, 2004.

16 Szmigiera E, Woyciechowski P, Experimental evaluation of the effect of bond in two-battened I shaped steel columns filled with concrete, Inżynieria i Budownictwo, 11, (2006), 618-621. in Polish.

17 Hallquist J O, LS-Dyna Keyword Manual, Version 9, Livermore Software Technology Corporation, 2007. 